Research Article

\title{
Development and In vitro Evaluation of a Zero Order Drug Releasing Transdermal System of Rotigotine
}

\author{
A. Sravanthi' ${ }^{1}$, Dr. M. Sunitha Reddy ${ }^{2}$, Dr. A. Jaswanth ${ }^{3}$ \\ ${ }^{1}$ Technical Trainer, Natco Pharma Limited, Hyderabad, Telangana, India. \\ ${ }^{2}$ Assistant Professor, Centre for Pharmaceutical Sciences, Institute of Science and Technology, JNTU-H, Hyderabad, Telangana, India. \\ ${ }^{3}$ Principal \& Professor, Surabhi Dayakar Rao College of Pharmacy, Siddipet, Telangana, India. \\ *Corresponding author's E-mail: sravanthianampally@gmail.com
}

Received: 08-11-2020; Revised: 17-12-2020; Accepted: 26-12-2020; Published on: 15-01-2021.

\begin{abstract}
Rotigotine is a new non-ergolinic dopamine agonist used in the treatment of Parkinson's disorder and restless legs syndrome. Oral administration of rotigotine is not suitable as it has extensive first pass metabolism (FPM). Administration of rotigotine through transdermal route is the best way to avoid FPM, to increase the bioavailability and to deliver the drug in a controlled rate for $24 \mathrm{~h}$. A controlled release transdermal system with zero order release kinetics was developed following a novel hybrid technique which includes a combination of micro reservoir and adhesive dispersion system. Transdermal system was prepared by incorporating rotigotine drug in adhesive matrix layer in which microspheres loaded with rotigotine were dispersed. Microspheres were prepared by spray drying technique using poly-e-caprolactone and maltodextrin (1:1 ratio) as carriers in various drug to polymer ratios. Microsphere composition comprising drug to polymer ratio 1:9 (formulation A5) was found to be more suitable for designing transdermal system as the composition showed desired particle size, yield, assay and in vitro drug release. Transdermal system was optimized by evaluating patch formulations prepared varying ratios of adhesive matrix and microsphere content ensuring the total drug content in the patch around $4.5 \mathrm{mg}$ following design of experiments (using application Statease Design Expert ${ }^{\circledR}$ ). The optimized transdermal formulation (F10) comprised of $80 \mathrm{mg}$ of silicon adhesive with $2.5 \mathrm{mg}$ of rotigotine along with $20 \mathrm{mg}$ of microspheres containing $2 \mathrm{mg}$ of rotigotine. The formulation F10 was subjected for stability as per ICH and was found stable up to six months at accelerated conditions. Rotigotine transdermal controlled release system was developed with desired release kinetic profile and stability.
\end{abstract}

Keywords: Rotigotine, micro reservoir, Parkinson's disorder, maltodextrin, polycaprolactone, microspheres.

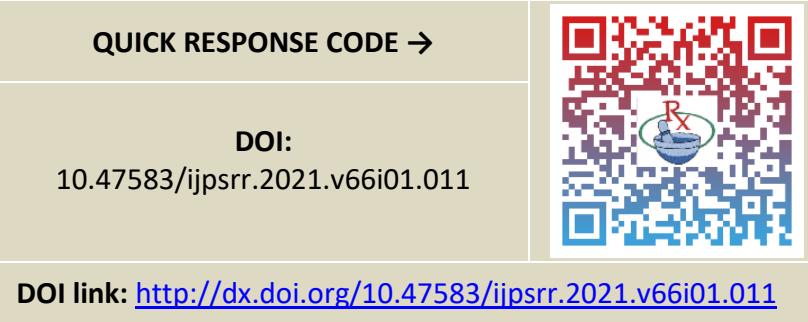

\section{INTRODUCTION}

otigotine is a non-ergolinic dopamine receptor agonist used in the treatment of Parkinson's disorder and moderate to severe restless legs syndrome $^{1,2}$. Parkinson's disease is a neurodegenerative disorder characterized by a progressive loss of dopaminergic neurons in the substantia nigra ${ }^{3}$. The two histopathologic features of Parkinson's disease are depigmentation of substantia nigra pars compacta indicates the loss of neurons responsible for producing dopamine and presence of levy bodies in the remaining neurons ${ }^{4}$. Rotigotine acts by activating dopamine receptors in the body, mimicking the effect of the neurotransmitter dopamine ${ }^{5,6}$. Due to an extensive first pass effect, rotigotine showed a very low oral bioavailability i.e., less than $1 \%$ in rodents $^{7}$. It is suitable candidate for transdermal delivery i.e., to avoid first pass metabolism and to enable continuous release for $24 \mathrm{~h}$. A zero order rotigotine release transdermal system provides stable extracellular rotigotine levels in the striatum, results in continuous stimulation of dopamine receptors ${ }^{8}$. It is an advantage in treatment of Parkinson's disorder compared with a pulsatile administration of rotigotine where motor complications induced by L-DOPA are observed ${ }^{9,10}$.

Transdermal drug delivery systems are extensively recognized drug delivery systems used in treatment of various diseases and disorders. Controlled release transdermal formulations may offer stable systemic drug concentrations avoiding first pass metabolism and enhance bioavailability. Utilization of transdermal drug delivery systems may be helpful especially in the treatment of Parkinson's disorder and restless leg syndrome. In this research an attempt was made to develop controlled release transdermal system of rotigotine following a novel method of designing a transdermal patch.

\section{MATERIALS AND METHODS}

Rotigotine USP (free base) was received as a gift sample from Neuland Pharma, Hyderabad. Poly-e-caprolactone of (MW 14000) was procured from Sigma Aldrich, Germany. Povidone K90 and Vitamin-E TPGS, Ascorbyl palmitate and D-Alpha tocopherol of USP-NF grade were procured from BASF, Germany. Maltodextrin (Glucidex IT17) of USP-NF 
grade was procured form Roquette Pharma, France. Sodium metabisulfite of Ph Eur grade was procured form Merck India. Aluminum vapor coated pigmented polyethylene polyester backing membrane (3M Scotchpack 1109) and Fluoropolyester coated release liner (3M Scotchpack 9744) were received as gift samples from 3M Corporation, USA. Silicon adhesive USP-NF grade (74302 BIO PSA) was procured from DOW Corning, USA. Solvents like methanol, ethyl acetate and dichloromethane of HPLC grade were procured from Merck, India. Ethanol 99.9\% was procured from Fisher Scientific, India.

\section{Method}

Controlled release transdermal system was developed following a novel hybrid technique which includes a combination of microreservoir system and adhesive dispersion system. The preparation of transdermal system was done as mentioned below:

\section{Preparation of rotigotine loaded microspheres}

2. Preparation of transdermal systems by incorporating rotigotine drug in adhesive matrix layer in which microspheres loaded with rotigotine were dispersed.
Rotigotine loaded microspheres were prepared by spray drying technique using poly-e-caprolactone and maltodextrin (1:1 ratio) as polymeric drug carriers. Microspheres were prepared varying ratios of drug to polymer mixture $(1: 5,1: 6,1: 7,1: 8,1: 9 \& 1: 10)$. Microspheres were prepared by dissolving poly-ecaprolactone in methanol, maltodextrin, Vitamin-E TPGS sodium metabisulfite in water, and rotigotine in ethanol. Thus three clear solutions were mixed and homogenized (Kinematica ${ }^{\circledR}$ Polytron PT 3100D) at 3000 rpm resulting in formation of an opaque dispersion. The dispersion was then spray dried in a spray drier of 4 inches internal diameter chamber (JISL, LSD-48) at a flow rate of $2.5 \mathrm{~mL}$ to $3.0 \mathrm{~mL}$ per minute using $1 \mathrm{~mm}$ spray nozzle maintaining inlet temperature, outlet temperature and product temperature at $110^{\circ} \mathrm{C}$ to $120^{\circ} \mathrm{C}, 60^{\circ} \mathrm{C}$ to $70^{\circ} \mathrm{C}$ and below 55 ㅇ $\mathrm{C}$ respectively. The atomization pressure was maintained at $30 \mathrm{PSI} \pm 3 \mathrm{PSI}$ and aspiration rate of -140 mmwc (1400 rpm in the machine). The dried microspheres obtained were collected and sealed in glass containers and were stored in desiccators until analysis ${ }^{11,}{ }^{12}$. The composition of microspheres $\left(A_{1}-A_{6}\right)$ are represented in Table 1.

\section{Preparation of rotigotine loaded microspheres}

Table 1: The composition of rotigotine loaded microspheres

\begin{tabular}{|c|c|c|c|c|c|c|}
\hline Formulation Code & $\begin{array}{c}\text { Drug: } \\
\text { Polymer }\end{array}$ & Drug (g) & $\begin{array}{c}\text { Polymeric } \\
\text { Carrier (g) }\end{array}$ & $\begin{array}{c}\text { Total Drug and } \\
\text { polymer mixture (g) }\end{array}$ & $\begin{array}{c}\text { Vitamin E } \\
\text { TPGS* (mg) }\end{array}$ & $\begin{array}{c}\text { Sodium } \\
\text { Metabisulfite* (mg) }\end{array}$ \\
\hline A1 & $1: 5$ & 0.75 & 3.75 & 4.5 & 11.25 & 11.25 \\
\hline A2 & $1: 6$ & 0.75 & 4.5 & 5.3 & 13.13 & 13.13 \\
A3 & $1: 7$ & 0.75 & 5.25 & 6.0 & 15.00 & 15.00 \\
A4 & $1: 8$ & 0.75 & 6 & 6.8 & 16.88 & 16.88 \\
A5 & $1: 9$ & 0.75 & 6.75 & 7.5 & 18.75 & 18.75 \\
A6 & $1: 10$ & 0.75 & 7.5 & 8.3 & 20.63 & 20.63 \\
\hline
\end{tabular}

Note: *Vitamin E TPGS and Sodium Metabisulfite were incorporated at $0.25 \%$ concentration with respect to the weight of drug and polymeric carrier mixture.

\section{Evaluation of rotigotine loaded microspheres}

The prepared microspheres were evaluated for various physical, chemical, drug release parameters and the procedures are mentioned below.

a) Description and appearance of microspheres It was evaluated by optical microscopy where the microspheres were ensured for spherical appearance and availability as separate individual entities.
The particle size was determined using optical microscopy ${ }^{13}$. The size distribution, average size of the microspheres was determined using an optical microscope (Olympus CX21i) fitted with an eye piece micrometer which was pre-calibrated with a stage micrometer. The size of about 100 microspheres was evaluated and the mean diameter was calculated. Particle size distribution analysis was performed for the determination of $D_{10}, D_{50}$ and $D_{90}$.

\section{b) Particle size distribution analysis}

$$
\text { Mean Particle Size }=\frac{\sum(\text { Mean Particle Size of the Fraction X Weight Fraction })}{\sum(\text { Weight Fraction })}
$$

c) Surface morphology by Scanning electron microscopy

Surface morphology was evaluated using Scanning electron microscope (Zeiss Sigma HDVP, Switzerland). Small quantities ( 5 to $10 \mathrm{mg}$ ) of microsphere samples were dispersed on a standard half inch diameter by half inch tall aluminium SEM specimen mount stubs aided with double stick carbon tape and were placed in the sputter coater chamber. The chamber was ensured a vacuum of $0.08 \mathrm{mbar}$ and samples were coated with gold for 10 minutes. The processed samples were placed in SEM chamber and examined 
for surface morphology under magnification of $1 \mathrm{KX}$ to $10 \mathrm{KX}$ at EHT $15.0 \mathrm{kV}$.

\section{d) Percentage Yield}

Practical yield of microspheres which indicates the efficiency of the method was calculated using the weight of the microspheres obtained from the batch in relation to the sum of the starting materials taken ${ }^{14}$.

$\%$ yield $=\frac{\text { The amount of microspheres obtained }}{\text { The theoretical amount }} \times 100$

e) Drug content

Percentage drug content in rotigotine loaded microspheres was determined by extracting the drug form the microspheres. $5 \mathrm{mg}$ rotigotine equivalent rotigotine loaded microspheres were taken in $25 \mathrm{~mL}$ volumetric flask to which $3 \mathrm{~mL}$ of Dichloromethane was added and allowed to disintegrate completely and then the volume was adjusted to $25 \mathrm{~mL}$ with solvent mixture of Methanol: Acetonitrile (1:1) ratio. The solution was sonicated for 15 minutes and was then filtered from 0.45 micron nylon filter. The filtered samples were analysed for drug content with HPLC.

\section{f) Encapsulation efficiency}

Encapsulation efficiency was evaluated by filter flush technique. $25 \mathrm{mg}$ of rotigotine equivalent microspheres (weight compensated after the determination of drug content by assay method) were taken in a sintered glass filter covered with zirconium beads of $0.5 \mathrm{~mm}$ and $1.0 \mathrm{~mm}$ diameter in 1:1 ratio by weight. $5 \mathrm{~mL}$ of ethanol was flushed over the surface of microsphere placed over the beads and solvent was allowed to flow down. The filtrate was collected from the bottom and evaluated for the free drug content eluted in it by HPLC method. Encapsulation efficiency was determined by deducting free drug content from actual drug content in microspheres and dividing it with the actual drug content and multiplied with $100^{15}$.

$$
\% \text { Encapsulation Efficiency }=\frac{\text { Actual drug content }- \text { Free Drug content in Eluent }}{\text { Actual drug content }} \text { X } 100
$$

g) Evaluation of amorphous nature of drug by X-Ray diffraction

For ensuring the presence of amorphous drug in microspheres the formulations were evaluated by $\mathrm{X}$ Ray diffraction. The drug containing microspheres (200 mg) were placed over the sample holder. The samples were then scanned from 0 to 50 2-Theta range at an angle of $0.020^{\circ}$ per step of 2.1 seconds.

\section{h) In vitro drug release studies}

In vitro drug release was performed using USP type II dissolution apparatus at $50 \mathrm{rpm}$ in $\mathrm{pH} 4.5$ acetate buffer. $25 \mathrm{mg}$ drug equivalent rotigotine loaded microspheres were filled in a size 1/size 2 capsules and were inserted in USP type spiral sinker. The sinker holding the capsule was dropped into the dissolution media before starting the agitation. During dissolution, samples were collected at 3 time points at every 1 hour interval i.e., at $1 \mathrm{~h}, 2 \mathrm{~h}$ and $3 \mathrm{~h}$. $5 \mathrm{~mL}$ of sample was collected at each time point. The samples were then filtered using 0.45 micron nylon filter and were analysed for drug content using HPLC.

\section{Preparation of transdermal patches}

Controlled release zero order release transdermal systems of rotigotine were developed by performing design of experiments study. Formulation optimization was performed by generating experiments applying central composite design using application Statease Design Expert $^{\circledR} 10$ USA.

\section{Study Design}

\section{Central Composite Design}

Central composite design was selected for the evaluation where the selected design model was pre-evaluated for design acceptability and the design was executed in 13 runs $^{16-18}$. The experiments were executed as per the design runs generated by the tool where two factors having three levels $(0, \pm 1)$ of formulation variables were considered i.e. $\mathrm{X}_{1}$ : Silicon adhesive $(65 \mathrm{mg}, 80 \mathrm{mg}$ and $95 \mathrm{mg}), \mathrm{X}_{2}$ :rotigotine loaded microsphere base (10 mg, $20 \mathrm{mg}$ and $30 \mathrm{mg}$ ). Influence of the selected variables was evaluated on four critical responses i.e. $Y_{1}$ (Thickness), $Y_{2}$ (Folding endurance), $\mathrm{Y}_{3}$ (Weight of the patch content) and $\mathrm{Y}_{4}$ (In vitro dissolution at $180 \mathrm{~min}$ ). The selected responses were considered for optimization and evaluated for design space establishment. The details of experiments generated are presented in the Table 2, 3, 4 and 5.

Table 2: Details of Experimental design followed for the study

\begin{tabular}{|c|c|c|}
\hline S. No & Parameter & Details \\
\hline 1 & Study Type & Response Surface \\
\hline 2 & Design Type & Central Composite \\
\hline 3 & Subtype & Randomized \\
\hline 4 & Runs & 13 \\
\hline 5 & Design Model & Quadratic \\
\hline
\end{tabular}


Table 3: Details of the factors evaluated by Design of Experiments

\begin{tabular}{|c|c|c|c|c|c|c|c|}
\hline Factor & Name & Units & Type & Min. & Max. & Mean & Std. Dev \\
\hline $\mathrm{X}_{1}$ & Silicon Adhesive & $\mathrm{mg}$ & Numeric & 65 & 95 & 80 & 10.61 \\
\hline $\mathrm{X}_{2}$ & Microsphere Base & $\mathrm{mg}$ & Numeric & 10 & 30 & 20 & 7.07 \\
\hline
\end{tabular}

Table 4: Details of the responses evaluated in the study

\begin{tabular}{|c|c|c|c|}
\hline Response & Name & Units & Analysis \\
\hline R1 & Thickness & Microns & Polynomial \\
\hline R2 & Folding endurance & No & Polynomial \\
\hline R3 & Weight of the patch content & $\mathrm{mg}$ & Polynomial \\
\hline R4 & Dissolution at $180 \mathrm{~min}$ & $\%$ & Polynomial \\
\hline
\end{tabular}

Table 5: Details of experiments generated using experimental design

\begin{tabular}{|c|c|c|c|}
\hline $\begin{array}{c}\text { Standard } \\
\text { order }\end{array}$ & Run & $\begin{array}{c}\text { Factor X1: } \\
\text { Silicon Adhesive } \\
\text { (mg) }\end{array}$ & $\begin{array}{c}\text { Factor X2: } \\
\text { Microsphere Base } \\
\text { (mg) }\end{array}$ \\
\hline 1 & 1 & 65 & 10 \\
\hline 2 & 6 & 95 & 20 \\
\hline 3 & 13 & 80 & 20 \\
\hline 4 & 4 & 95 & 30 \\
\hline 5 & 5 & 65 & 20 \\
\hline 6 & 10 & 80 & 20 \\
\hline 7 & 3 & 65 & 30 \\
\hline 8 & 11 & 80 & 20 \\
\hline 9 & 12 & 80 & 20 \\
\hline 10 & 9 & 80 & 20 \\
\hline 11 & 8 & 80 & 30 \\
\hline 12 & 7 & 80 & 10 \\
\hline 13 & 2 & 95 & 10 \\
\hline
\end{tabular}

\section{Preparation of Transdermal systems of Rotigotine}

Rotigotine containing adhesive layer was prepared by mixing silicon adhesive with antioxidants (sodium metabisulfate, ascorbyl palmitate, and Vitamin E TPGS $\alpha$ tocopherol), Rotigotine drug substance, methanol, ethyl acetate and polyvinyl pyrrolidone. To the above clear solution weighed amount of Rotigotine containing microspheres were added and mixed. Then above mixture was casted over a backing membrane and dried for $24 \mathrm{~h}$. The release liner was then laid on the adhesive side and the system was cut into patches of suitable size.

\section{B) Evaluation of microspheres loaded adhesive dispersion patches}

\section{General appearance}

The appearance and surface integrity of the patches was observed with naked eye and by using a 20X magnifying glass. The patch formulation was separated from backing membrane and placed over a transparent PVC sheet and was observed for the texture and description.

\section{Thickness}

The thickness of the whole patch including release liner was determined at six different points using digital micrometer. The thickness of the backing membrane and release liner were measured before casting drug containing adhesive solution on to it. Actual thickness of the drug containing adhesive matrix was calculated with the following formula:

Thickness of the Drug Containing Adhesive Matrix

$=$ Thickness of the whole patch system

- (Thickness of the backing membrane

+ Thickness of the release liner)

\section{Weight variation}

Six patches were selected randomly and weighed individually on a semi-microbalance (Sartorius TE-124, Germany) then the release liner and backing membrane (by washing out the drug matrix with solvent) from each patch system was separated and weighed individually. The together weight of the release liner and backing membrane was subtracted from the whole weight of the patch system for obtaining the drug matrix layer weight. Accordingly after 6 determinations the average weight of the patch was calculated.

Weight of the drug matrix layer $=$ Weight of the whole patch system - (weight of the backing membrane

+ Weight of the release liner)

\section{Determination of the drug content of the patch}

A patch of $3.569 \mathrm{~cm}$ diameter or $3.163 \mathrm{~cm}(/ x b)$ having a surface area of $10 \mathrm{~cm}^{2}$ was extracted in $100 \mathrm{~mL}$ of methanol for $2 \mathrm{~h}$. The solution was then filtered and analysed by RP-HPLC method (Waters 2695, USA). Three replicate measurements were performed for each formulation.

\section{Moisture uptake studies}

The prepared patches were evaluated for moisture absorbing capacity. Six patches were selected randomly, weighed individually and kept in a desiccator containing $100 \mathrm{~mL}$ of saturated solution of aluminum chloride at room temperature for $24 \mathrm{~h}$ which maintains the $\mathrm{RH}$ of $79.5 \%$. The 
patch was weighed periodically till it showed a constant weight. \% moisture uptake was calculated using following formula.

$$
\% \text { Moisture uptake }=\frac{\text { Final weight of the patch }- \text { Initial weight of the patch }}{\text { Initial weight of the patch }} \times 100
$$

\section{Moisture content determination}

Six patches from each formulation were selected and weighed individually. Then release liners from each patch were removed and weighed separately. The liner separated patches were spread on a mesh and kept in a desiccator containing anhydrous calcium chloride at room temperature, the weight of each patch was monitored after every 6 hours till they showed a constant weight. \% Moisture content was determined using following equation.

$$
\% \text { Moisture content }=\frac{\text { Initial weight of the patch }- \text { Final weight of the patch }}{\text { Final weight of the patch }} \times 100
$$

\section{Flatness}

Flatness of the patch was determined to evaluate the constriction behaviour of the patch after application on to the skin. The transdermal patches were cut into longitudinal strips, length of each strip was measured initially and after keeping aside. Variation in the length of the patch was determined using formula for \% constriction. Zero \% constriction is equivalent to $100 \%$ flatness.

$$
\% \text { Constriction }=\frac{\text { Initial length of the patch }- \text { Final length of the patch }}{\text { Final length of the patch }} \times 100
$$

\section{Folding endurance}

Folding endurance is a value indicating the number of times the patch could be folded at same place without any crack/break. Six patches of each formulation $(2 \mathrm{~cm} \times 2 \mathrm{~cm})$ were selected randomly and were folded in a repeated manner at the same place till it broke. The number of times the film was folded at the same place without braking gave the folding endurance value.

\section{Measurement of mechanical properties}

Mechanical properties of the patches were evaluated using a fabricated tensile strength testing apparatus shown in Figure 1. Film strip with dimensions of $60 \times 10 \mathrm{~mm}$ was held in between two clamps. Then weights were added in the pan which led to elongation of patch. The force required for breaking of the patch is noted (F).

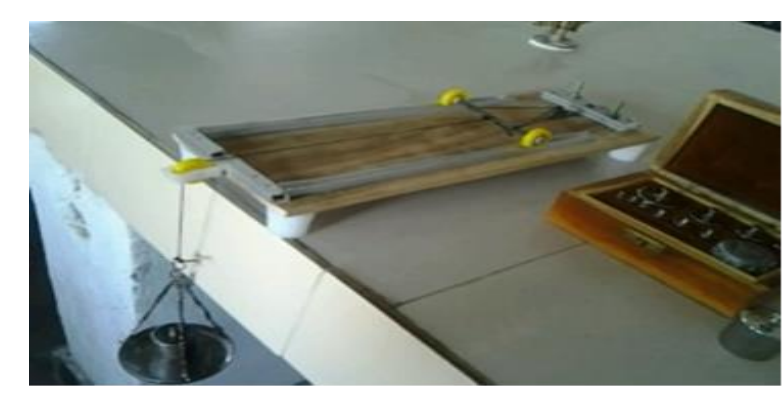

Figure 1: Fabricated instrument to determine mechanical properties of the patch

Mechanical properties of the patch were calculated using the following formulae.

Tensile Strength $\left(\mathrm{kg} / \mathrm{mm}^{2}\right.$

$$
=\frac{\text { Force at break }(\mathrm{kg})}{\text { Initial cross sectional area of the sample }\left(\mathrm{mm}^{2}\right)}
$$

Elongation at break $\left(\% \mathrm{~mm}^{2}\right)$

$$
=\frac{\text { Increase in lenght }(\mathrm{mm})}{\text { Original Lenght }(\mathrm{mm})} \times \frac{100}{\text { Cross sectional area }}
$$

\section{Evaluation of hardness of the patch}

Hardness of the patch was determined using fabricated instrument shown in Figure 2. Hardness testing apparatus consists of a wooden stand of $8 \mathrm{~cm}$ in height and a top area of $8 \times 8 \mathrm{~cm}$. A hole of $0.2 \mathrm{~cm}$ diameter is made in the centre of the wooden top. A small metallic pan of diameter $6 \mathrm{~cm}$ is fixed on one end of a $2 \mathrm{~mm}$ thick smooth iron rod. Rod having the pan on its upper end is inserted into the hole of the wooden top and its lower sharp end was placed on a metal plate. Battery of $3 \mathrm{~V}$ was used to make an electric circuit. Assembly was set in such a way that the bulb lights up only when the circuit is complete via the contact of the metal plate and the sharp end of the rod.

The patch (release liner removed) was placed (drug matrix layer facing towards rod) between the metal plate and the sharp end of the iron rod and the weights were gradually added on to the pan and total weight required to penetrate the patch is indicated by the lighted bulb.

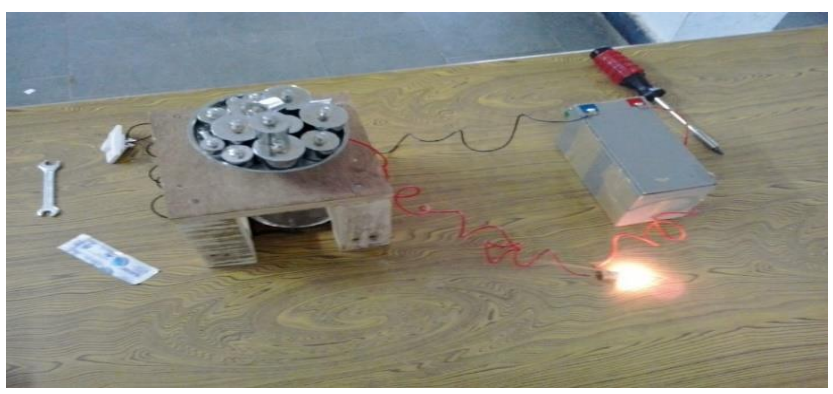

Figure 2: Fabricated instrument to determine hardness of the patch 


\section{Microscopic examination}

The presence of drug substance in crystalline form in the formulation was evaluated preliminarily using optical microscope aided with $15 \mathrm{X}$ eyepiece and 40X, 100X objective. (Model, Olympus CX 21i). Pictograms of the transdermal system surface was taken using camera (Model, Magcam DC 5) connected to the microscope.

\section{X-Ray diffraction for amorphosity confirmation}

The rotigotine transdermal systems were prepared by stabilizing drug substance in amorphous form. For ensuring the presence of amorphous drug in the transdermal system the formulations were evaluated for presence of crystalline drug substance by X-Ray diffraction. The drug containing adhesive layer was stripped out from the backing membrane and placed over the sample holder. The samples were scanned from 0 to 50 2-Theta range at an angle of 0.020 o per step of 2.1 seconds.

\section{In vitro dissolution studies}

In vitro dissolution study was conducted using USP Type 5 apparatus i.e. paddle over disc. Transdermal patch holder with 17 mesh screen was used to hold the release liner separated patch and it was dropped in the dissolution medium $(900 \mathrm{~mL})$ at temperature $32 \pm 0.5 \circ \mathrm{C}$. Apparatus was maintained with paddle speed of $50 \mathrm{rpm}$ and samples were withdrawn periodically i.e. after $15,30,60,90,120$, 150 and $180 \mathrm{~min}$.

\section{Mathematical modelling of release kinetics}

To understand the release kinetics from the formulated patches, the release data was fitted into various kinetic models.

\section{Stability study}

Stability study was conducted as per ICH guidelines Q1A (R2).The formulations F10, F11 \& F12 were subjected for stability of six months. After stability period the patches were evaluated for physical appearance/description, assay, \% impurities and \% drug release.

\section{RESULTS AND DISCUSSION}

\section{Rotigotine Loaded Microspheres:}

\section{Description}

Rotigotine microspheres were prepared varying drug to carrier ratio (carrier - polycaprolactone: maltodextrin in 1:1 ratio). The prepared microspheres were found to be discrete and spherical in shape. The microspheres were noticed to be free flowing and existed as individual entities without any agglomerates.

\section{Particle Size Distribution}

Average particle size distribution of the prepared rotigotine loaded microspheres were found to be ranging from $11 \mu \mathrm{m}$ to $18 \mu \mathrm{m}$. Increase in the polymer ratio didn't affect the particle size. It indicates the key role of spray drying parameters in controlling the particle size of microspheres. The results were presented in the Table 6 .

\section{Surface morphology by scanning electron microscopy}

The SEM images of rotigotine loaded microspheres were found to be with satisfactory description. Images of evaluated microspheres were presented in Figure 3.

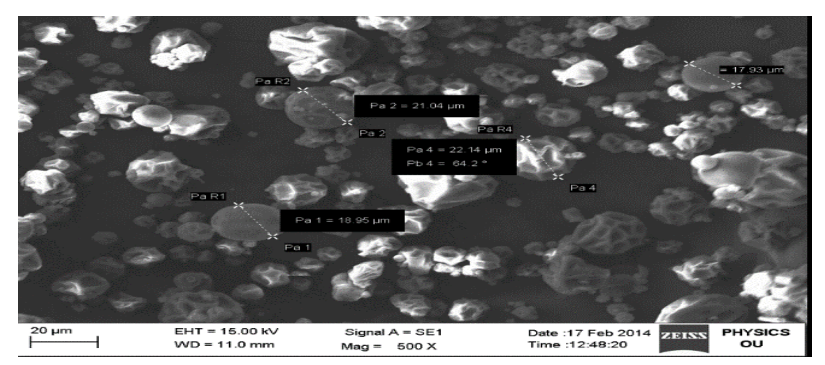

Figure 3: Scanning Electron microscope image of Rotigotine microspheres

\section{Percentage yield}

Yield of various rotigotine loaded microsphere formulations were found in the range of $68.6 \%$ to $78.7 \%$. Among the prepared microsphere formulations, the formulation (A5) with Drug (rotigotine): carrier ratio of 1:9 was found to be with maximum yield i.e., around $78.7 \%$ and the least yield was obtained in the formulation prepared at Drug (rotigotine): carrier of 1:8 ratio. The data is presented in the Table 6.

\section{Drug Content by Assay}

Drug content \% in the rotigotine loaded microsphere formulations was evaluated by HPLC. The \% drug content in various microsphere formulations was found ranging from $95.4 \%$ to $99.6 \%$. The maximum \% drug content was obtained in the formulation (A5) with 1:9 Drug (rotigotine): carrier ratio. The results are presented in the Table 6.

\section{Encapsulation efficiency}

Encapsulation efficiency in various microsphere formulations were found to be ranging from $47.69 \%$ to $97.12 \%$. The formulations prepared at drug: carrier mixture ratio of $1: 9$ and $1: 10$ were found to be with high encapsulation efficiency. Results are presented in Table 6.

\section{Evaluation of amorphosity of drug in rotigotine loaded microspheres by X-Ray diffraction}

Among the prepared rotigotine loaded microsphere formulations, compositions prepared at Drug: Carrier mixture ratio of 1:8 $\left(A_{4}\right), 1: 9\left(A_{5}\right)$ and 1:10 $\left(A_{6}\right)$ were found to be existing in amorphous state. Whereas the formulation prepared with drug: carrier mixture ratio of less than 1:8 were found to be with crystalline drug moiety where rotigotine specific intense peaks were found to be observed in X-ray diffractogram at various 2-Theta values. The formulations found to be with crystalline drug moiety were ruled out and not considered for further screening. 


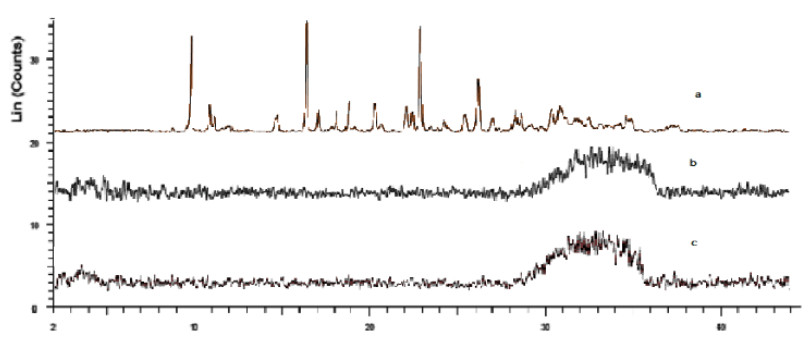

Figure 4 (a): X Ray diffractogram of the Rotigotine As such API (b) X Ray Diffractogram of Microsphere formulation (A5) showing amorphous nature (c) X Ray Diffractogram of Microsphere formulation (A5) showing amorphous nature after 6 months accelerated stability at 40 으

\section{In vitro drug release studies}

Among the prepared rotigotine loaded microspheres, formulations prepared at Drug: Carrier mixture ratio of 1:8, $1: 9$ and $1: 10$ were evaluated for in vitro drug release where the maximum release of rotigotine within 3 hours was found to be in formulations prepared with Drug: Carrier ratio of 1:8 (A4) and 1:9 (A5) i.e., around $99.21 \%$ to $99.36 \%$ whereas the formulation prepared at drug: carrier mixture ratio of $1: 10$ (A6) showed retardation and only $93.16 \%$ release after 3 hours. Results are presented in the Table 6.

Table 6: Parameters evaluated during screening of rotigotine microsphere formulations

\begin{tabular}{|c|c|c|c|c|c|c|c|}
\hline S. No & Code (D:MB) & $\begin{array}{c}\text { Mean particle } \\
\operatorname{Size}(\mu)\end{array}$ & Yield (\%) & Assay (\%) & $\begin{array}{l}\text { Encapsulation } \\
\text { Efficiency (\%) }\end{array}$ & Crystallinity & $\begin{array}{c}\text { In vitro } \\
\text { Drug release at } 3 \mathrm{~h}(\%)\end{array}$ \\
\hline 1 & A1 (1:5) & 12 & 70.6 & 97.5 & 47.69 & Exists & Ruled out \\
\hline 2 & A2 (1:6) & 18 & 73.5 & 98.6 & 65.15 & Exists & Ruled out \\
\hline 3 & A3 (1:7) & 16 & 75.9 & 96.9 & 73.20 & Exists & Ruled out \\
\hline 4 & A4 (1:8) & 11 & 68.6 & 95.4 & 87.92 & Not Exists & 99.21 \\
\hline 5 & A5 (1:9) & 15 & 78.7 & 99.6 & 96.80 & Not Exists & 99.36 \\
\hline 6 & A6 (1:10) & 13 & 71.2 & 98.1 & 97.12 & Not Exists & 93.16 \\
\hline
\end{tabular}

From the results obtained, the microspheres from A5 batch was considered to be optimized and used for incorporation into the adhesive layer of transdermal patch following design of experiments.

\section{B) Evaluation of micro reservoir loaded adhesive} dispersion patches:

\section{General appearance/description}

The patch was found to be thin, opaque, smooth homogenous and flexible when observed with naked eye, shown in Figure 5.

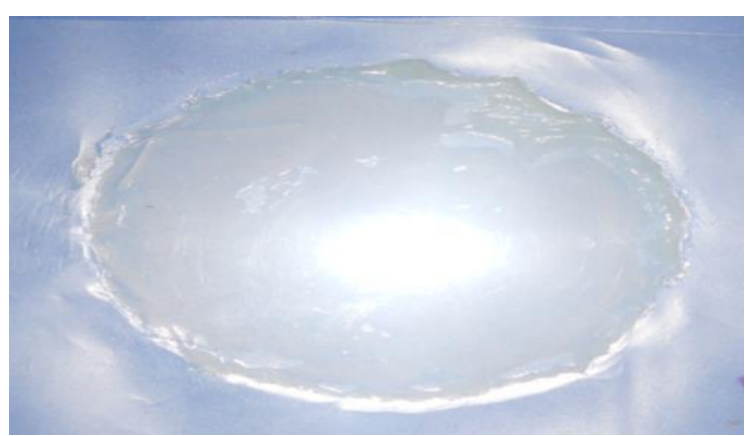

Figure 5: The texture and description of the patches (after separating from backing membrane)

\section{Thickness}

The thickness of the transdermal systems was uniform and ranged from $0.116 \pm 0.016 \mathrm{~mm}$ to $0.299 \pm 0.042 \mathrm{~mm}$. Results were presented in Table 7.

\section{Weight variation}

The weight of transdermal patches was found to be in the range of $0.081 \pm 0.0025 \mathrm{~g}$ to $0.128 \pm 0.0056 \mathrm{~g}$. The standard deviation values of the patches were low which indicates weight variation among the prepared transdermal systems was found to be low. Results were presented in Table 7.

\section{Microscopic examination}

The surface of the patch was found to be uniform and there was no evidence of crystallization when observed under microscope. The pictogram was shown in Figure 6.

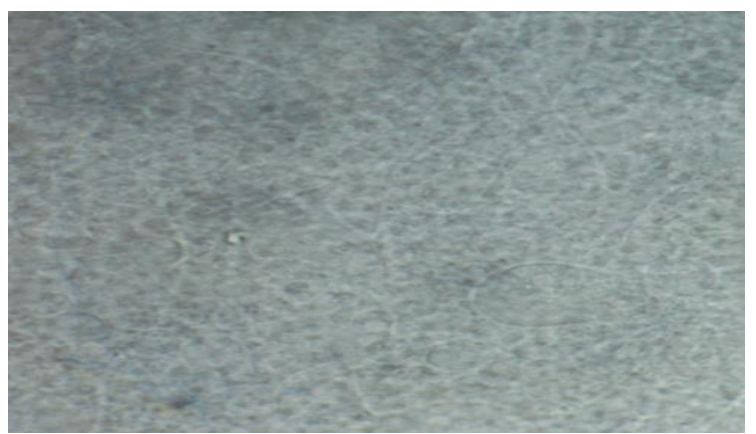

Figure 6: The texture and description of the patches under microscope (20X) magnification

\section{Drug content uniformity}

Drug content of the patches was determined using RPHPLC technique and was found to be in the range of $90.46 \pm 3.44 \%$ to $102.78 \pm 4.28 \%$. Less standard deviation values indicates more uniformity in drug 
content of the patches. Results were presented in Table 7.

\section{Moisture absorption}

The average moisture uptake was found to be in the range of $2.786 \pm 0.452 \%$ and $4.142 \pm 0.329 \%$. Absorption of the moisture by the patch upon exposure to $84 \% \mathrm{RH}$ did not influence much but, the transdermal patches were to be stored in moisture barrier foil since mild increase in moisture gain was observed. Results were presented in Table 7.

\section{Moisture content}

The average \% moisture content of the transdermal patches was found to be in the range of $0.96 \pm 0.253 \%$ to $1.78 \pm 0.328 \%$. Less moisture content indicates higher stability of the patches. Results were presented in Table 7.

\section{Flatness}

Flatness indicates level of immediate constriction of the patches. The flatness study proved that all the formulations had the same strip length before and after cutting/separation which indicates $100 \%$ flatness of the patch. Thus, the patch has no level of immediate constriction and same could be maintained when applied on the skin. Results were presented in Table 7.

\section{Folding Endurance}

The study showed that all the formulations found to have folding endurance value above 250 indicating the patches were having good strength, elasticity and can maintain their integrity when applied on to the skin. Results were presented in Table 7.

Table 7: Parameters evaluated for rotigotine transdermal formulations

\begin{tabular}{|c|c|c|c|c|c|c|c|}
\hline $\begin{array}{c}\text { Formulation } \\
\text { Code }\end{array}$ & Thickness $(\mathbf{m m})$ & Weight variation $(\mathbf{g})$ Drug content (\%) & \%oisture uptake & $\begin{array}{c}\text { \% Moisture } \\
\text { content }\end{array}$ & \% Flatness & $\begin{array}{c}\text { Folding } \\
\text { endurance }\end{array}$ \\
\hline F1 & $0.116 \pm 0.016$ & $0.081 \pm 0.0025$ & $95.06 \pm 2.89$ & $3.782 \pm 0.891$ & $1.26 \pm 0.132$ & $100 \%$ & $<250$ \\
\hline F2 & $0.238 \pm 0.029$ & $0.108 \pm 0.0043$ & $97.35 \pm 3.67$ & $2.786 \pm 0.452$ & $1.19 \pm 0.026$ & $100 \%$ & $>250$ \\
\hline F3 & $0.119 \pm 0.038$ & $0.103 \pm 0.0021$ & $102.78 \pm 4.28$ & $4.142 \pm 0.329$ & $1.28 \pm 0.037$ & $100 \%$ & $>250$ \\
\hline F4 & $0.299 \pm 0.042$ & $0.128 \pm 0.0056$ & $101.92 \pm 4.36$ & $3.782 \pm 0.338$ & $1.39 \pm 0.111$ & $100 \%$ & $<250$ \\
\hline F5 & $0.159 \pm 0.026$ & $0.091 \pm 0.0038$ & $95.29 \pm 5.63$ & $4.025 \pm 0.254$ & $0.98 \pm 0.112$ & $100 \%$ & $<250$ \\
\hline F6 & $0.128 \pm 0.042$ & $0.103 \pm 0.0067$ & $99.42 \pm 3.78$ & $2.891 \pm 0.378$ & $1.31 \pm 0.315$ & $100 \%$ & $>250$ \\
\hline F7 & $0.186 \pm 0.056$ & $0.093 \pm 0.0029$ & $90.46 \pm 3.44$ & $3.823 \pm 0.436$ & $1.47 \pm 0.402$ & $100 \%$ & $<250$ \\
\hline F8 & $0.211 \pm 0.043$ & $0.105 \pm 0.0067$ & $98.65 \pm 5.46$ & $2.992 \pm 0.265$ & $1.68 \pm 0.318$ & $100 \%$ & $>250$ \\
\hline F9 & $0.184 \pm 0.028$ & $0.104 \pm 0.0061$ & $96.59 \pm 4.49$ & $3.764 \pm 0.189$ & $1.05 \pm 0.261$ & $100 \%$ & $>250$ \\
\hline F10 & $0.167 \pm 0.039$ & $0.101 \pm 0.0027$ & $102.29 \pm 3.99$ & $3.673 \pm 0.365$ & $0.96 \pm 0.253$ & $100 \%$ & $>250$ \\
\hline F11 & $0.119 \pm 0.028$ & $0.111 \pm 0.0038$ & $99.92 \pm 4.05$ & $3.227 \pm 0.478$ & $1.58 \pm 0.298$ & $100 \%$ & $>250$ \\
\hline F12 & $0.221 \pm 0.041$ & $0.095 \pm 0.0031$ & $98.78 \pm 3.06$ & $3.877 \pm 0.204$ & $1.78 \pm 0.328$ & $100 \%$ & $>250$ \\
\hline F13 & $0.296 \pm 0.029$ & $0.104 \pm 0.0056$ & $96.48 \pm 4.49$ & $2.976 \pm 0.307$ & $1.66 \pm 0.227$ & $100 \%$ & $>250$ \\
\hline
\end{tabular}

\section{In vitro dissolution studies}

In vitro dissolution study was conducted using USP-5 dissolution test apparatus i.e., paddle over disc apparatus using $900 \mathrm{~mL}$ phosphate buffer of $\mathrm{pH} 4.5$ as the dissolution media. Among all, three formulations were found satisfactory on which further studies were carried out $\left(F_{10}\right.$, $\left.F_{11} \& F_{12}\right)$ and maximum release was observed from F10 patch. Drug release plots were represented in Figure 7.

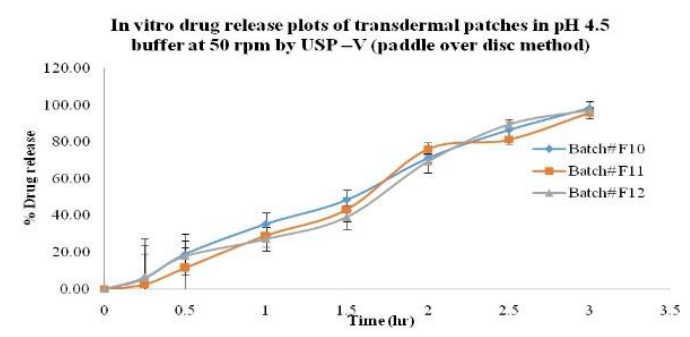

Figure 7: In vitro drug release plots of transdermal patches in $\mathrm{pH} 4.5$ buffer

\section{Mechanical Properties}

Mechanical properties indicates the strength and elasticity of the transdermal patches. The low values of tensile strength and elongation at break indicates that the polymer is soft and weak and vice-versa. A suitable transdermal patch must have high tensile strength and elongation at break. The results indicates that as the polymer concentration increased, there was increase in tensile strength but decrease in elongation at break. The optimized formulation (F10) was found to have high mechanical strength. The mechanical properties of most promising transdermal formulations F10, F11\& F12 were presented in the Table 8. 
Table 8: Mechanical properties of transdermal formulations F10, F11\& F12

\begin{tabular}{|c|c|c|} 
Formulation & $\begin{array}{c}\text { Tensile strength } \\
\left(\mathbf{k g} / \mathbf{m m}^{\mathbf{2}}\right)\end{array}$ & $\begin{array}{c}\text { Elongation at break } \\
\left(\mathbf{\% m ^ { 2 }}\right)\end{array}$ \\
\hline F10 & $3.56 \pm 0.035$ & $15.92 \pm 0.39$ \\
\hline F11 & $2.75 \pm 0.028$ & $13.78 \pm 0.41$ \\
\hline F12 & $2.91 \pm 0.046$ & $13.56 \pm 0.76$ \\
\hline
\end{tabular}
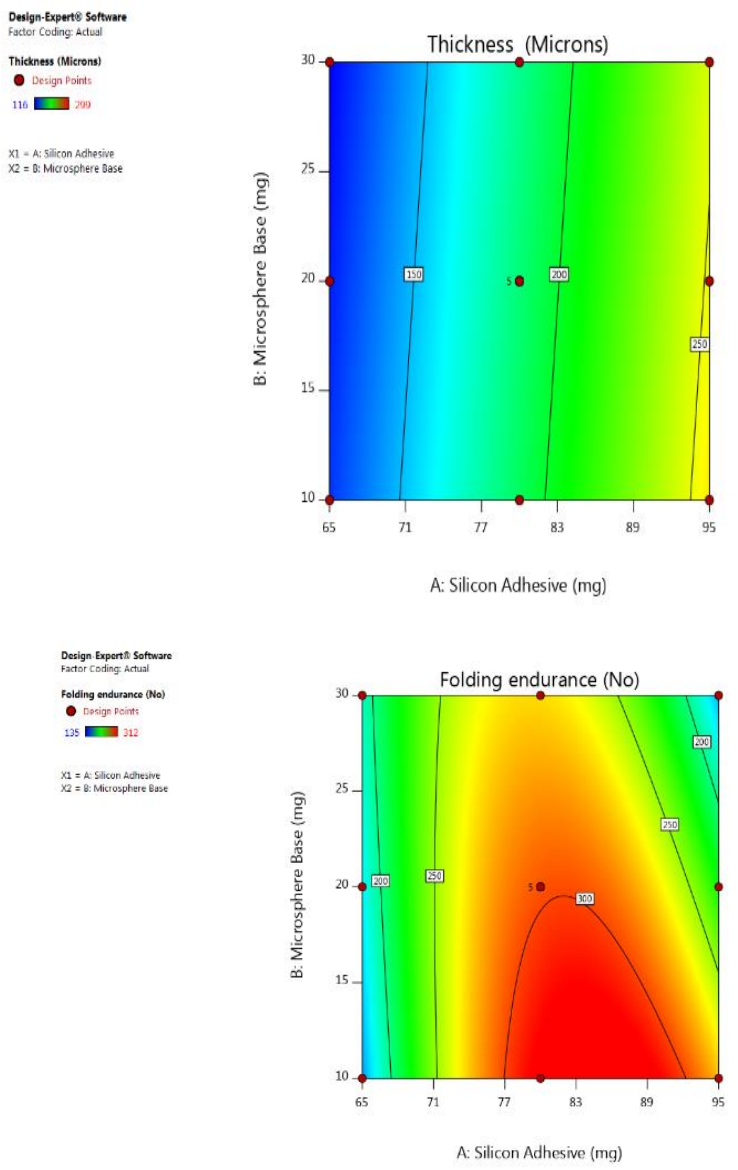

Figure 8: Contour plot showing the relationship between various levels of two factors on thickness and folding endurance

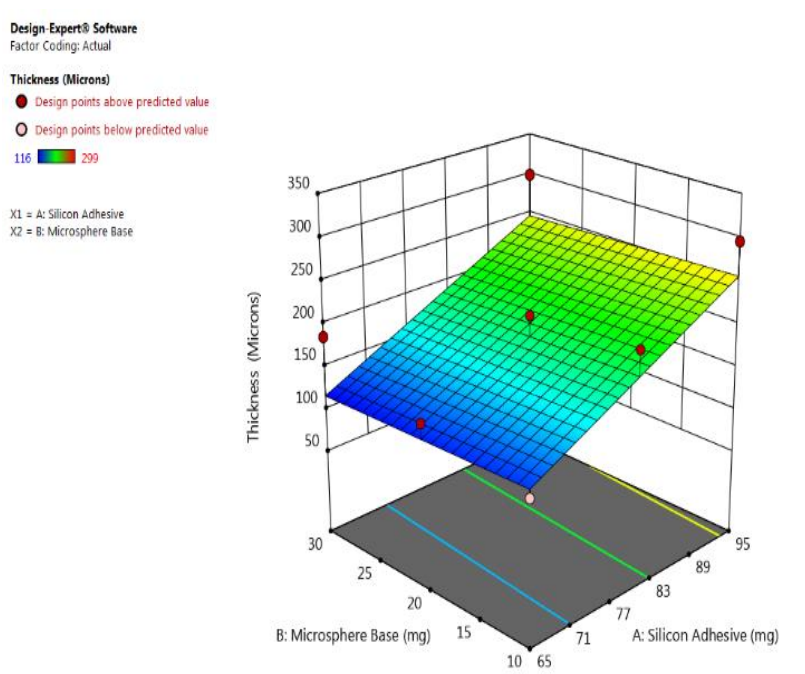

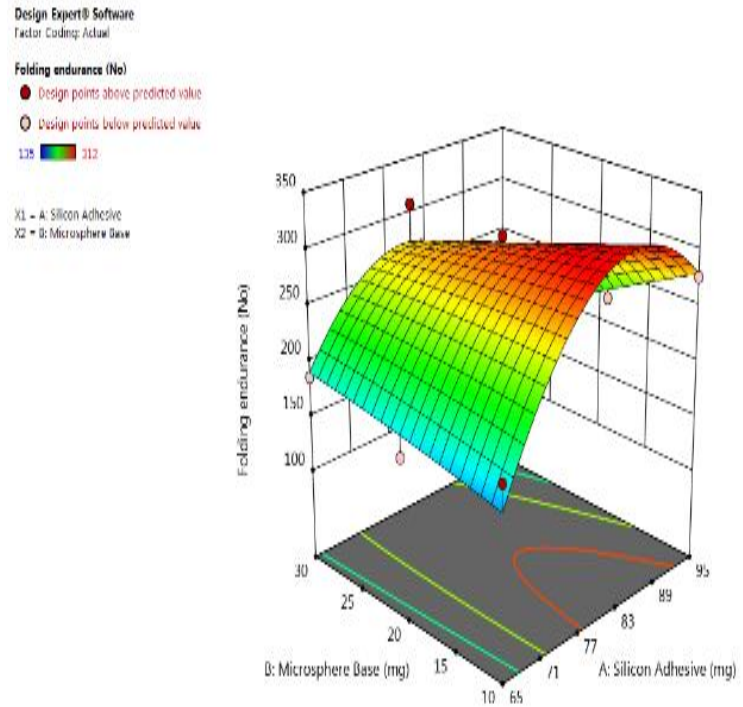

Figure 9: Response surface plot showing the influence of Microsphere base and Silicon Adhesive on thickness and folding endurance

The impact of silicon adhesive and microsphere base was found to be varied on various responses like thickness, folding endurance, weight and assay of the formulation. To get an optimum ratio of silicon adhesive and microsphere base for obtaining best fit satisfactory responses, numerical optimization was performed where the optimum ratios of factors was identified with maximum desirability i.e., upon taking $75.323 \mathrm{mg}$ of silicon adhesive and $17.957 \mathrm{mg}$ of microsphere base produces a formulation with $98.40 \%$ of assay, $96.6 \mathrm{mg}$ of weight, 167micron thick patch and with a folding endurance of 282.88 times. Hence the optimized formulation was found with satisfactory physical parameters.

\section{Mathematical modelling of release kinetics}

The in vitro drug release data was fit into various models and the results were presented in Table 9.

\section{Stability study}

Thermal Stability of formulations was evaluated for 6 months in accelerated, intermediate and real time conditions. The patches subjected for stability were then evaluated for Description, \% Assay and \% drug release and the data presented in the Table 10. 
Table 9: Release Kinetics of transdermal formulations F10, F11\& F12

\begin{tabular}{|c|c|c|c|c|c|c|c|c|c|c|}
\hline \multirow{2}{*}{$\begin{array}{l}\text { Formulation } \\
\text { code }\end{array}$} & \multicolumn{2}{|c|}{ Zero order } & \multicolumn{2}{|c|}{ First order } & \multicolumn{2}{|c|}{ Higuchi } & \multirow[t]{2}{*}{ Best fit } & \multicolumn{2}{|c|}{$\begin{array}{c}\text { Korsemeyer - } \\
\text { Peppas }\end{array}$} & \multirow[t]{2}{*}{ Mechanism } \\
\hline & $R^{2}$ & $k_{o}$ & $R^{2}$ & $k_{1}$ & $R^{2}$ & $k_{H}$ & & $R^{2}$ & $n$ & \\
\hline F10 & 0.9937 & 2.4295 & 0.9898 & 0.0151 & 0.9629 & 14.213 & $\begin{array}{l}\text { Zero } \\
\text { Order }\end{array}$ & 0.9958 & 1.0431 & $\begin{array}{c}\text { Super Case II } \\
\text { Transport }\end{array}$ \\
\hline F11 & 0.9541 & 2.1369 & 0.9617 & 0.0129 & 0.9488 & 12.271 & $\begin{array}{l}\text { First } \\
\text { Order }\end{array}$ & 0.9633 & 0.7366 & $\begin{array}{l}\text { Case II } \\
\text { Transport }\end{array}$ \\
\hline F12 & 0.9298 & 2.7341 & 0.9515 & 0.0179 & 0.9303 & 16.073 & $\begin{array}{l}\text { First } \\
\text { Order }\end{array}$ & 0.9358 & 0.8896 & $\begin{array}{l}\text { Case II } \\
\text { Transport }\end{array}$ \\
\hline
\end{tabular}

Table 10: Stability Study data of transdermal formulations F10, F11\& F12

\begin{tabular}{|c|c|c|c|c|c|c|c|}
\hline \multirow{3}{*}{$\begin{array}{l}\text { Formulation } \\
\text { Code }\end{array}$} & \multirow{3}{*}{ Parameter } & \multicolumn{6}{|c|}{ Temperature/Relative Humidity (RH) } \\
\hline & & \multicolumn{2}{|c|}{$25 \pm 2^{\circ} \mathrm{C} / 60 \pm 5 \% \mathrm{RH}$} & \multicolumn{2}{|c|}{$30 \pm 2^{\circ} \mathrm{C} / 65 \pm 5 \% \mathrm{RH}$} & \multicolumn{2}{|c|}{$40 \pm 2^{\circ} \mathrm{C} / 75 \pm 5 \% \mathrm{RH}$} \\
\hline & & Initial & $6 \mathrm{M}$ & Initial & $6 \mathrm{M}$ & Initial & $6 \mathrm{M}$ \\
\hline \multirow{3}{*}{ F10 } & Description & Good & Good & Good & Good & Good & Good \\
\hline & Assay (\%) & 102.29 & 101.98 & 102.29 & 99.86 & 102.29 & 98.46 \\
\hline & \%Drug Release (3h) & 98.67 & 97.65 & 98.67 & 96.68 & 98.67 & 95.86 \\
\hline \multirow{3}{*}{ F11 } & Description & Good & Good & Good & Good & Acceptable & Acceptable \\
\hline & Assay (\%) & 99.92 & 98.65 & 99.92 & 97.89 & 99.92 & 95.56 \\
\hline & \%Drug Release (3h) & 97.21 & 96.45 & 97.21 & 95.68 & 97.21 & 92.65 \\
\hline \multirow{3}{*}{ F12 } & Description & Good & Good & Good & Acceptable & Good & Acceptable \\
\hline & Assay (\%) & 98.78 & 97.65 & 98.78 & 96.56 & 98.78 & 92.57 \\
\hline & \%Drug Release (3h) & 97.18 & 96.85 & 97.18 & 95.55 & 97.18 & 92.14 \\
\hline
\end{tabular}

\section{CONCLUSION}

A controlled release transdermal system with zero order release kinetics was developed following a novel hybrid technique which includes a combination of micro reservoir and adhesive dispersion system. Transdermal system was optimized by evaluating patch formulations prepared by varying ratios of adhesive matrix and microsphere content following design of experiments (using application Statease Design Expert ${ }^{\circledR}$ ).The optimized formulation was found stable up to six months when subjected for stability as per ICH guidelines.

\section{REFERENCES}

1. Lewitt PA, Lyons KE, Pahwa R, Advanced Parkinson disease treated with rotigotine transdermal system: PREFER Study, Neurology, 2007; 68(16): 1262-1267.

2. Trenkwalder C, Efficacy of rotigotine for treatment of moderate-to-severe restless legs syndrome: a randomised, double-blind, placebo-controlled trial, Lancet Neurol, 2008; 7(7): 595-604.

3. Waters $\mathrm{C}$. The development of the rotigotine transdermal patch: a historical perspective, 2013; 31(3 Suppl): S37-50.

4. Chen JJ, Swope DM, Dashtipour K, Lyons KE, Transdermal rotigotine: A clinically innovative dopamine-receptor agonist for the management of Parkinson's disease, Pharmacotherapy, 2009; 29(12): 1452-1467.
5. Pham DQ, Nogid A. Rotigotine transdermal system for the treatment of Parkinson's disease, Clinical Therapeutics, 2008; 30(5): 813-824.

6. Cawello W, Kim SR, Braun M, Elshoff JP, Ikeda J, Funaki T. Pharmacokinetics, safety and tolerability of rotigotine transdermal patch in healthy Japanese and Caucasian subjects, Clin Drug Investig, 2014; 34: 95-105.

7. Splinter YM, Rotigotine: Transdermal Dopamine agonist treatment of Parkinson's disease and restless legs syndrome. Annals of Pharmacotherapy, 2007; 41: 285-295.

8. Kolster KS, Kohnen R, Schollmayer E, Moller JC, Oertel WH, Patch application of the Dopamine agonist rotigotine to patients with moderate to advanced stages of restless legs syndrome: A double-blind, placebo-controlled pilot study, Movement Disorders, 2004; 19(12): 1432-1438.

9. Schmidt $W J$ et al, Continuous versus pulsatile administration of rotigotine in 6-OHDA-lesioned rats: contralateral rotations and abnormal involuntary movements, J Neural Transm, 2008; 115: 1385-1392.

10. Kehr J, Hu XJ, Goiny M, Scheller DKA, Continuous delivery of rotigotine decreases extracellular dopamine suggesting continuous receptor stimulation, J Neural Transm, 2007; 114: 1027-1031.

11. Giunchedi P, Conti B, Maggi L, Conte U, Cellulose acetate butyrate and polycaprolactone for ketoprofen spray dried microsphere preparation, J Microencapsulation, 1994; 11: 381-393. 
12. Harikarnpakdee S, Lipipun V, Sutanthavibul N, Ritthidej GC, Spray dried mucoadhesive microspheres: Preparation and transport through nasal cell monolayer, AAPS PharmSciTech, 2006; 7(1): E1-E10.

13. Rai SY, Ravikumar P, Development and evaluation of microsphere based topical formulation using design of experiments, Indian J Pharm Sci, 2016; 78(2): 182-192.

14. Prashanth VV, Chakraborty A, Mathew S, Mathappan R, Kamalakkannan, Formulation and evaluation of salbutamol sulphate microspheres by solvent evaporation method, J Appl Pharm Sci. 2011; 01(05): 133-137.

15. Venkatesh DP, Karki R, Jha SK, Lakshmi AG, Kumar GSS, Goli D. Formulation and evaluation of microspheres containing fluvastatin sodium. Int J Drug Dev Res, 2012; 4(2): 306-314.
16. Dhiman S, Verma S, Optimization of melt-in-mouth tablets of levocetrizine dihydrochloride using response surface methodology, Int J Pharm Sci, 2012; 4(1): 177-184.

17. Bose A, Wong TW, Singh N, Formulation development and optimization of sustained release matrix tablet of Itopride $\mathrm{HCl}$ by response surface methodology and its evaluation of release kinetics, Saudi Pharm J, 2013; 21: 201-213.

18. Bushra R, Shoaib $M H$, Ali $H$, Zafar F, Formulation design and optimization of Aceclofenac tablets $(100 \mathrm{mg})$ using central composite design with response surface methodology, Latin American Journal of Pharmacy, 2014; 33(6): 10091018.

Source of Support: None declared.

Conflict of Interest: None declared.

For any question relates to this article, please reach us at: editor@globalresearchonline.net New manuscripts for publication can be submitted at: submit@globalresearchonline.net and submit_ijpsrr@rediffmail.com 